\title{
Teacher Motivation and Job Satisfaction in Greek Primary Schools
}

\author{
Maria Darra ${ }^{1}$
}

\begin{abstract}
:
The main aim of this paper is to examine the views of primary education teachers, in relation to both the prioritisation of the significance of specific factors related to the satisfaction of teachers, and to the determination of the degree of significance of the parameters that contribute to their motivation in their workplace, as well as in relation to the determination of the extent to which specific work factors contribute to their disappointment at work. The findings of this research point to the conclusion that the majority of respondents place the factors related to support on behalf of the school management, observance of the school's rules of operation, and the existence of an internal operating regulation as the top three priorities. In contrast, the existence of a written school development plan and social recognition rank last in the respondents' priority list. Moreover, it is established that the motivation of teachers is linked primarily to internal factors of professional satisfaction, among which the most important are the respondents' interest in their work, work-related creativity and freedom of action. Finally, it is concluded that the main factors of respondent disappointment in their work are mostly exogenous and are identified as the lack of appropriate material infrastructure, insufficient funding of school units and lack of satisfaction in their earnings.
\end{abstract}

\section{Keywords:}

Teacher Motivation, Teacher Job Satisfaction, Primary Schools, Endogenous Factors of Work Satisfaction, Exogenous Factors

JEL Classification: I21 I25

\footnotetext{
1 Lecturer, University of the Aegean, Department of Education, Creece e-mail: jckaza1989@yahoo.gr
} 


\section{Introduction}

The achievement of a school's aims is linked directly to the satisfaction of teachers, which, in turn, has been linked to work motives, attitudes and values (Vaxevanidou $\&$ Reklitis, 2000). The importance of professional satisfaction is undoubtedly pronounced; moreover, over the past three decades, many studies both in Greece and internationally have attempted to determine the factors of teacher satisfaction/ dissatisfaction and motivation, (Darra, 2006; Eliophotou-Menon, Papanastasiou \& Zempylas, 2008).

Particularly, as regards the issue of teacher professional satisfaction, motivation and professional dissatisfaction with/ disappointment in their work, the following has been sustained:

According to the relationship model (Gruneberg, 1979), job satisfaction is a comprehensive result linked to a variety of processes and factors. All these factors, such as working conditions, roles and responsibilities, the personality of the teacher and his/ her demographic data are linked directly to his/ her professional satisfaction. On the contrary, "the depressing and repulsive climate conveys a feeling of decay and disappointment, negatively affects the quality of work offered by the teacher and consequently minimises the effectiveness of the school unit" (Saitis, 2008).

As pertains to the level of professional satisfaction of Greek teachers, most studies (Koustelios \& Tsiligis, 2005 [for physical education teachers]; Koustelios, 2001 [for primary and secondary school teachers]; Koustelios, Tsiligis, Zachopoulou, Grammatikopoulos, 2006 [for nursery teachers]) report that this level ranges from medium to high.

Similarly, the research of Rhodes, Nevill \& Allan (2004) on the professional satisfaction and dissatisfaction of primary and secondary school teachers has shown that, in order to achieve a high level of professional satisfaction, the following are needed: good relations with colleagues; work aimed at achieving common targets; possibility to exchange experiences with colleagues; a climate of success prevailing at the school; and a comprehensive effort towards effective knowledge.

Also, based on the results of the research conducted by Dinham \& Scott (1998), public school teachers in Australia stated that their satisfaction was related to the performance of their pupils and their personal professional development. In contrast, low levels of satisfaction were linked by the respondents to their workload, their social status, the prestige of teachers and meritocratic promotions. Leadership, communication and decision-making are also noteworthy factors. 
The research of Macmillan \& Ma, X. (1999) on teachers in Canada has shown that the professional satisfaction of teachers is linked in a positively way to the conditions of their workplace and, more in particular, to management supervision, the teacher's didactic competence and his/ her organisational culture.

Kantas (1992), in a research carried out with the participation of 269 secondary education teachers, has found that the professional satisfaction of teachers depends mainly on the profession per se and on the nature of work it entails, as well as on the social relations that exist in the profession. On the contrary, the main sources of their dissatisfaction are to be found in their pecuniary rewards and in the prospects of progress and personal development that are linked to their profession.

Matsaggouras \& Makri-Mpotsari (2003) researched the degree of professional satisfaction and self-esteem of Greek teachers, as well as the factors contributing to the formation thereof. The results show that primary education teachers declare a high degree of overall professional satisfaction, contributing factors of which are, in descending order: satisfaction derived from the relations with their supervisors; satisfaction from the social status of the teaching profession; and satisfaction from the freedom of choice of their work methods. Factors external to the work, such as salary, did not contribute significantly to the projection of a comprehensive professional satisfaction. Similarly, based on the study results, the teachers state a high degree of self-esteem, which is related to professional competence, intelligence, relations with colleagues, creativity and administrative-organisational skills.

On the basis of the above findings, and given that: (a) teacher professional satisfaction, motivation and disappointment/ dissatisfaction are factors that co-exist, are inter-related and altogether determine the effectiveness of the educational process; (b) professional satisfaction is an incentive for the teacher to make a continuous effort to improve the content of his/ her didactic work, so as to become more effective by also contributing to the achievement of educational aims; and (c) in order to improve teacher professional satisfaction, it is imperative, inter alia, to also enhance/ improve intra-school factors that are linked to the context of the working life of teachers, at the micro-level of the school unit, while of particular importance is also the examination of the teachers' views in relation to the endogenous factors of professional satisfaction/ dissatisfaction and to the motivation, in relation to their job.

In this paper, we shall make some initial theoretical references to matters pertaining to professional satisfaction/ dissatisfaction and motivation of teachers and, subsequently, we shall present and analyse the findings of our empirical research. 


\section{Theoretical Context}

Teacher professional satisfaction is considered as one of the fundamental factors affecting the performance of teachers and, by extension, the effectiveness and correct function of the school unit. Even though the research efforts reported thus far approach the phenomenon of professional satisfaction in a different manner, researchers agree that professional satisfaction is a multidimensional conceptual construct which consists of many individual elements (Koustelios, 2001; Matsaggouras and Makri-Mpotsari 2003), without however refuting the existence of a comprehensive satisfaction pattern, resulting from work in general.

The most used definition for professional satisfaction is that of Locke (1976), who describes it as a pleasant or otherwise positive emotional condition, deriving from the assessment of someone's work or work experiences; contrarily, professional dissatisfaction is the result of the cancellation of the individual's work values.

The term teaching professional satisfaction relates to the emotional relation of the educator with his/ her teaching role, and is a function of the perceived relation between the educator's expectation from his/ her teaching role and what he/ she perceives as being offered to him/ her by this role (Zembylas \& Papanastasiou, 2004). It is stressed, finally, that despite the different approaches, many researchers consider that professional satisfaction is self-evident and that, consequently, very few have attempted to formulate a strict conceptual and functional definition of the term (Evans, 1999).

The factors that contribute to professional satisfaction or dissatisfaction and that are also expressed with the term sources of satisfaction are related either with the work content, or with the context within which such work is being provided. Such factors are, for instance earnings, autonomy and relations with colleagues (Makri-Mpotsari \& Matsaggouras, 2003).

These factors can be divided into endogenous and exogenous, in relation to work. Some researchers, such as Herzberg, use the term motives to describe the endogenous factors. In the field of education, the relationship between professional satisfaction and incentives is very important for a long-term development of any educational system worldwide. Incentives and professional satisfaction are both related to professional knowledge and skills, abilities, educational sources and strategies, as actual determining factors of educational success and performance. According to Herzberg (in Kantas, 1998), the factors (incentives) of work satisfaction are: achievement, recognition of work, the work per se, accountability, and career prospects. 
Based on Warr (2005), endogenous factors of work satisfaction include characteristics related to the nature of work, its content and its dimensions. Such characteristics are: (a) interest in one's work; (b) freedom of choice in performing one's work; (c) the diversity and variety of one's activities; (d) the utilisation of one's skills; (e) the degree of accountability involved in the completion of one's project; (f) opportunities for personal control (independence, self-determination); (g) perspicuity of one's working environment (clarification of the job description, information on the consequences of specific behaviours, information on the progress of a specific project); (h) feedback (information on the effectiveness of one's work); (i) one;s participation in decision-making; (j) the significance of the project in question; (k) one's promotion opportunities; (l) one's recognition from colleagues and society at large, etc. (Grammatikou, 2010).

The exogenous factors, the non-existence of which is a potential source of dissatisfaction, are: earnings, inter-personal relations, the policy of the organisation and the management model, supervision and working conditions. According to Herzberg, eliminating the exogenous factors does not guarantee the professional satisfaction of the individual. This is achievable only by endogenous factors, i.e. the five factors of motives mentioned above (Makri-Mpotsari \& Matsaggouras, 2003).

The link between motivation and professional satisfaction is to be found in expectancy theory, coined by Vroom (1964) who dealt with what determines the individual's intention to put personal effort on work. This effort contributes to the performance of the department or of the entire organisation he/ she works in. He posits that the professional motivation of an individual is determined by: (a) what he/ she believes about the effort-performance relation (expectancy); (b) what he/ she believes about the work and results relation (instrumentality); and (c) how much he/ she looks forward to the results of his/ her work. More specifically, teacher professional satisfaction is related directly with the quality and the stability of their teaching work, as well as with their effectiveness, which ultimately affects pupil performance.

Thus far, it is clear that there can be no professional satisfaction disassociated from motivation: these phenomena are inter-linked and directly affect one another. Besides, motivation is a process that stimulates, activates, directs and finally empowers the individual's behaviour and performance. Also, it is a truism that in order for teachers to be able to perform their educational tasks successfully, they must feel satisfied with their job. Dinham \& Scott (2000) refer to a new model of professional satisfaction (based on Herzberg's theory) and propose a third category of factors including factors on the level of the school system, as well as of wider social forces. More specifically, they stress that, in order to improve teacher professional satisfaction, it is necessary to enhance the intra-school factors that relate to the school climate, the leadership behaviour of the school unit manager, the 
school's infrastructure and its prestige. These factors can be controlled and determined by the schools alone, as well as by their managers who exercise a leadership role.

The lack of professional satisfaction can be studied as a cause of burnout (professional exhaustion), and vice versa. The issue of burnout has been studied over the past two decades. The most widely used definition of burnout is the one proposed by the psychologist Maslach (1982, qt. in Koustelios \& Kousteliou, 2001). Along this line of thought, burnout is a syndrome of physical and psychological exhaustion, in the context of which the employee loses his/ her interest and ceases to draw satisfaction from his/ her job, while also developing negative feelings for his/ herself and his/ her job. According to Maslach and Jackson (1986), the factors that contribute to burnout are related to psychological exhaustion of the employee, who in turn loses his/ her energy to invest in his/ her job. This results in the individual developing impersonal relations in his/ her working environment and, ultimately, reducing his/ her work performance and thus being unable to handle significant issues.

Finally, as regards the relation between professional satisfaction and burnout, there are three approaches (Maslach \& Schaugeli 1993:11). The first approach posits that burnout is the cause of the decline of professional satisfaction, considering that an employee's psychological exhaustion deprives him/ her of the energy that is necessary form him/ her to invest in his/ her job. The second approach considers that professional disappointment entails burnout. Certainly, if there is tension in the relations between teachers and their pupils, the school manager or other faculty members, there is also emotional exhaustion and, naturally, a change of behaviour and disappointment. The third view stresses that professional disappointment and professional satisfaction can be caused both by adverse working conditions related to the impersonal and institutional working conditions and the material and technical infrastructure, as well as by increased job requirements, the limited role of the employees in decision-making, increased work insecurity, and, finally, imbalance between effort and reward.

\section{Aim and Research Questions}

The main aim of this paper is to examine the views of primary school teachers, on the one hand in relation to the prioritisation of the significance of specific factors of satisfaction, regarding the context of the teachers' working life at the micro-level of the school unit and the school class and to the determination of the degree of significance of the parameters contributing to their motivation in their workplaces, as well as, on the other hand, in relation to how the degree to which specific job factors contribute to their disappointment from their work is determined. 
A basic assumption of our study is that the professional satisfaction of teachers is affected by internal school factors related to the context of the working life of teachers, at the micro-level of the school unit, and that the effect of these factors is linked directly to the motivation of teachers and the effectiveness of the educational work produced by the school unit examined.

The research attempts to address individual questions as follows:

1. How do the teachers of our sample value the significance of specific factors of satisfaction related to the context of the working life of teachers, at the micro-level of the school unit and the school class?

2. How do the teachers of our sample value the degree of significance of the basic parameters that contribute to their motivation in their working environment?

3. To what extent do the teachers of our research sample consider that specific job factors contribute to their disappointment in their work?

4. Which proposals could be made by the teachers of our sample in relation to their satisfaction derived from the content of their work, as well as to the means of their motivation for improving the effectiveness of their work?

\section{Methodology}

The research was carried out during the second semester of the 2012-2013 school year, using an anonymous written questionnaire that was filled out by 89 primary school teachers at the prefecture of Viotia.

The questionnaire of our research consists of four (4) parts. The first part concerns the collection of demographic data. The second part includes six questions, all related to the staff and personal characteristics of the teachers of the schools that took part in the research. The third part includes three questions, concerning elements of satisfaction, motivation and disappointment of the teachers from their work. Finally, the fourth part includes an open-ended question, based on which the primary school teachers of our sample were asked to formulate their proposals in relation to the means of their motivation for improving the effectiveness of their work.

The analysis of the questionnaires was performed using cross-tabs with appropriate $\mathrm{x}^{2}$ controls, so as to examine if there are statistically significant differences in the percentages between groups. In carrying out these controls, the level of statistical significance used was a $=0.05(5 \%)$. Using the cross-tabs procedure, the possible relations between specific variables are examined. 


\section{Research Results Presentation}

\subsection{Teacher sample data}

Based on the research data, the following findings are derived pertaining to the sample of teachers who filled out the questionnaires, in relation to the structure of their schools, their sex and age, their total years of service, the years of service at the school where the respondents are currently employed, their family status, their post at the school and their educational qualifications.

In relation to the structure of the school units, the majority of respondents (58.8\%) work at medium-sized schools (employing 6 teachers), while $41.2 \%$ work at large schools (employing 10-12 teachers). In addition, the majority of teachers $(44.7 \%)$ work at schools in urban areas; $18.8 \%$ at schools located in semi-urban areas; and $36.5 \%$ at schools located in rural areas.

In relation to their sex (question 1), the majority of respondents (85.2\%) are women, and $14.8 \%$ are men.

In relation to their age (question 2), a large percentage of respondents (65.2\%) are aged up to 40 years; $30.3 \%$ falls in the $41-50$ age group; and a mere $4.5 \%$ is 51 years or above.

In relation to the total years of service in public education (3a), 30.2\% has 1-5 years; $33.7 \%$ has $6-10$ years; $20.9 \%$ has $11-20$ years; and $15.1 \%$ has 21 years or above in the public education system.

As regards the respondents' years of service at the school where they are currently employed (3b), the majority of them (59.8\%) have served from $1-3$ years; $12.6 \%$ has served between 4 and 8 years; and $27.6 \%$ has served for more than 8 years.

As regards their family status (question 4), the majority of respondents (58.4\%) are married, $39.3 \%$ are unmarried and $2.2 \%$ replied "other".

As regards the respondents' post at their school (question 5), the majority of teachers (79.8\%) have a permanent position; $10.1 \%$ are seconded; and a further $10.1 \%$ are adjunct staff.

Finally, with regard to the teachers' educational qualifications (question 6), the majority of respondents $(71.9 \%)$ is a University or Technological Educational Institute graduate; a mere $7.9 \%$ holds a master's degree; and $4.5 \%$ state also having followed other courses of study. 


\subsection{Data related to the satisfaction and motivation of teaching staff}

In question (7) "which of the following factors related to satisfaction from your work do you consider as more important?" the respondents' answers vary in relation to specific factors, which they were asked to evaluate (see Table 1).

The Table below depicts the significance of endogenous factors of the satisfaction of teachers, based on the prioritisation of the factors which the sample teachers made. To better highlight the prioritisation of the factors' significance, the table below presents for each individual factor:

- the significance prioritisation coefficient;

- the percentage of teachers who prioritised the factor in question as first;

- the percentage of teachers who placed the factor in the first three positions; and

- the percentage of teachers who placed the factor in the last (10th) and the penultimate $\left(9^{\text {th }}\right)$ position.

The prioritisation coefficient of the significance of each factor was calculated by dividing the sum of all prioritisation numbers of the factor by the number of teachers. It goes without saying that if (theoretically) all of the teachers placed any given factor in the first $\left(1^{\text {st }}\right)$ position, then the significance prioritisation coefficient would be equal to $1(89=89)$.

Table 1: Frequency distribution (\%) of the teachers and significance prioritisation coefficients based on their response to the question regarding the significance of specific factors of satisfaction from their work (Significance prioritisation)

\begin{tabular}{|c|c|c|c|c|c|}
\hline & $\begin{array}{l}\text { Significance of factors of } \\
\text { satisfaction from work }\end{array}$ & $\begin{array}{c}\text { Significance } \\
\text { prioritisation } \\
\text { coefficients (1-10) }\end{array}$ & $\begin{array}{c}1 s t \\
\text { choice } \\
\text { Freq. } \%\end{array}$ & $\begin{array}{c}\text { 1st, 2nd } \\
\text { and } 3 r d \\
\text { choice } \\
\text { Freq. } \% \\
\end{array}$ & $\begin{array}{c}\text { 9th and } \\
10 \text { th } \\
\text { choice } \\
\text { Freq. \% } \\
\end{array}$ \\
\hline a. & $\begin{array}{l}\text { observance of the school operating } \\
\text { rules }\end{array}$ & 7.2 & $\begin{array}{c}9 \\
10.3 \%\end{array}$ & $\begin{array}{c}55 \\
63.1 \%\end{array}$ & $\begin{array}{c}3 \\
3.4 \%\end{array}$ \\
\hline b. & stability of the faculty & 4.43 & $\begin{array}{c}2 \\
2.4 \%\end{array}$ & $\begin{array}{c}15 \\
20 \%\end{array}$ & $\begin{array}{c}30 \\
36.2 \%\end{array}$ \\
\hline c. & $\begin{array}{l}\text { existence of a written school } \\
\text { development plan }\end{array}$ & 4.081 & $\begin{array}{c}1 \\
1.2 \%\end{array}$ & $\begin{array}{c}16 \\
19.7 \%\end{array}$ & $\begin{array}{c}34 \\
42 \%\end{array}$ \\
\hline d. & $\begin{array}{l}\text { existence of an internal operating } \\
\text { regulation }\end{array}$ & 7.104 & $\begin{array}{c}8 \\
9.3 \%\end{array}$ & $\begin{array}{c}49 \\
57 \%\end{array}$ & $\begin{array}{c}9 \\
10.5 \%\end{array}$ \\
\hline e. & interest of your colleagues & 5.075 & $\begin{array}{c}3 \\
3.4 \%\end{array}$ & $\begin{array}{c}22 \\
24.9 \%\end{array}$ & $\begin{array}{c}10 \\
11.4 \%\end{array}$ \\
\hline f. & $\begin{array}{l}\text { recognition of your work by the } \\
\text { parents }\end{array}$ & 5.215 & $\begin{array}{c}7 \\
8.2 \% \\
\end{array}$ & $\begin{array}{c}18 \\
21 \% \\
\end{array}$ & $\begin{array}{c}11 \\
13 \% \\
\end{array}$ \\
\hline g. & support by the parents & 5.593 & $\begin{array}{c}2 \\
2.4 \% \\
\end{array}$ & $\begin{array}{c}28 \\
33 \% \\
\end{array}$ & $\begin{array}{c}26 \\
30.5 \% \\
\end{array}$ \\
\hline h. & support by the school & 8.039 & 39 & 46 & 9 \\
\hline
\end{tabular}




\begin{tabular}{|l|l|c|c|c|c|}
\hline & management & & $44.3 \%$ & $52.2 \%$ & $10.2 \%$ \\
\hline i. & social recognition & 3.634 & 2 & 16 & 36 \\
& & & $2.4 \%$ & $19.2 \%$ & $43.4 \%$ \\
\hline j. & sense of job security & 5.113 & 17 & 21 & 21 \\
& & & $19.5 \%$ & $24 \%$ & $24.1 \%$ \\
\hline
\end{tabular}

In question (8) "to what extent do you consider that the following elements constitute important motivating factors in relation to your work?" the replies of the respondents are presented in Table 2.

Table 2: Distribution of frequencies and relative \% of teachers according to their response on the evaluation of the degree of significance of the motivation factors in relation to the satisfaction from their work

\begin{tabular}{|l|l|c|c|c|c|}
\hline no. & Motivating factors in the workplace & High & Average & Low & Not at all \\
\hline a. & freedom of action & 64 & 22 & 2 & 0 \\
& & $72.7 \%$ & $25 \%$ & $2.3 \%$ & \\
\hline b. & work creativity & 67 & 20 & 2 & 0 \\
& & $75.3 \%$ & $22.5 \%$ & $2.2 \%$ & \\
\hline c. & interest for one's work & 74 & 14 & 1 & 0 \\
& & $83.1 \%$ & $15.7 \%$ & $1.1 \%$ & \\
\hline d. & satisfaction from one's earnings & 39 & 29 & 11 & 9 \\
& & $44.3 \%$ & $33 \%$ & $12.5 \%$ & $10.2 \%$ \\
\hline e. & professional development prospects & 26 & 42 & 16 & 4 \\
& & $29.5 \%$ & $47.7 \%$ & $18.2 \%$ & $4.5 \%$ \\
\hline f. & Recognition & 33 & 41 & 11 & 0 \\
& & $38.8 \%$ & $48.2 \%$ & $12.9 \%$ & \\
\hline g. & need for success & 28 & 41 & 18 & 0 \\
& & $32.2 \%$ & $47.1 \%$ & $20.7 \%$ & \\
\hline h. & existence of a culture of support, & 53 & 33 & 0 & 0 \\
\hline i. & solidarity and mutual understanding & $61.6 \%$ & $38.4 \%$ & & \\
& connection of personal development with & 46 & 35 & 7 & 0 \\
\hline professional development & establishment of continuous & $52.3 \%$ & $39.8 \%$ & $8 \%$ & \\
\hline improvement processes at work & 53 & 27 & 5 & 0 \\
\hline
\end{tabular}

In question (9) "to what extent do you consider that the following factors contribute to disappointment from your work?", the replies are presented in Table 3.

Table 3: Distribution of frequencies and relative $\%$ of teachers according to their response on the degree of their disappointment from specific factors related to their work

\begin{tabular}{|l|l|c|c|c|c|}
\hline no. & Factors of disappointment from work & High & Average & Low & Not at all \\
\hline a. & inadequate training at the level of & 26 & 42 & 16 & 2 \\
& basic studies & $30.2 \%$ & $48.8 \%$ & $18.6 \%$ & $2.3 \%$ \\
\hline b. & lack of appropriate material and & 36 & 53 & 0 & 0 \\
& technical infrastructure & $40.4 \%$ & $59.6 \%$ & & \\
\hline c. & insufficient information about & 26 & 49 & 11 & 2 \\
& institutionalised educational changes & $29.5 \%$ & $55.7 \%$ & $12.5 \%$ & $2.3 \%$ \\
\hline
\end{tabular}




\begin{tabular}{|l|l|c|c|c|c|}
\hline d. & exclusion from decision-making & 38 & 34 & 14 & 2 \\
& centres & $43.2 \%$ & $38.6 \%$ & $15.9 \%$ & $2.3 \%$ \\
\hline e. & lack of appropriate further training & 41 & 38 & 9 & 0 \\
& programmes & $46.6 \%$ & $43.2 \%$ & $10.2 \%$ & 0 \\
\hline f. & inadequate school unit funding & 62 & 25 & 0 & 0 \\
& & $71.3 \%$ & $28.7 \%$ & & \\
\hline g. & lack of satisfaction from one's earnings & 57 & 31 & 0 & 0 \\
& & $64.8 \%$ & $35.2 \%$ & & \\
\hline h. & conflicts at the workplace & 60 & 17 & 3 & 6 \\
& & $69.8 \%$ & $19.8 \%$ & $3.5 \%$ & $7 \%$ \\
\hline
\end{tabular}

Combining the above findings with the total years of service in the public education system (question 3a), it is concluded that the number of teachers who replied that the existence of conflicts at the workplace is a factor contributing highly or averagely to their disappointment from work, is differentiated in relation to the years of service in the public education system variable, also presenting an upwardly trend in the categories having fewer years of service. Therefore, it can be sustained that teachers with fewer years of service reply that the existence of conflicts at the workplace is a factor that contributes significantly or averagely to disappointment from work (see Table 4). It should be noted that the Pearson chi-square control value is 25.595 at a level of observed statistical significance equalling 0.002 (Table: Chi-Square Tests).

Table 4: Correlation of the total years of service in the educational system and of the existence of conflicts at the workplace, as a factor contributing to teacher disappointment from their work

\begin{tabular}{|c|c|c|c|c|c|c|c|}
\hline \multirow{2}{*}{\multicolumn{3}{|c|}{$\begin{array}{l}\text { Total years of service in the } \\
\text { educational system * The existence of } \\
\text { conflicts at the workplace, as a factor } \\
\text { contributing to their disappointment } \\
\text { from work. Cross-tabulation }\end{array}$}} & \multicolumn{4}{|c|}{$\begin{array}{l}\text { The existence of conflicts at the workplace, } \\
\text { as a factor contributing to their } \\
\text { disappointment from work }\end{array}$} & \multirow[b]{2}{*}{ Total } \\
\hline & & & High & Average & Low & $\begin{array}{c}\text { Not at } \\
\text { all }\end{array}$ & \\
\hline \multirow{8}{*}{$\begin{array}{l}\text { Total years of } \\
\text { service in the } \\
\text { educational } \\
\text { system }\end{array}$} & \multirow[t]{2}{*}{$1-5$ years } & Count & 18 & 7 & 0 & 0 & 25 \\
\hline & & $\begin{array}{l}\% \text { of } \\
\text { Total }\end{array}$ & $21.7 \%$ & $8.4 \%$ & $0 \%$ & $0 \%$ & $30.1 \%$ \\
\hline & \multirow[t]{2}{*}{$6-10$ years } & Count & 18 & 7 & 0 & 2 & 27 \\
\hline & & $\begin{array}{l}\% \text { of } \\
\text { Total }\end{array}$ & $21.7 \%$ & $8.4 \%$ & $0 \%$ & $2.4 \%$ & $32.5 \%$ \\
\hline & \multirow[t]{2}{*}{$11-20$ years } & Count & 15 & 0 & 3 & 0 & 18 \\
\hline & & $\begin{array}{l}\% \text { of } \\
\text { Total }\end{array}$ & $18.1 \%$ & $0 \%$ & $3.6 \%$ & $0 \%$ & $21.7 \%$ \\
\hline & \multirow[t]{4}{*}{$21+$ years } & Count & 7 & 3 & 0 & 3 & 13 \\
\hline & & $\begin{array}{l}\% \text { of } \\
\text { Total }\end{array}$ & $8.4 \%$ & $3.6 \%$ & $0 \%$ & $3.6 \%$ & $15.7 \%$ \\
\hline \multirow[t]{2}{*}{ Total } & & Count & 58 & 17 & 3 & 5 & 83 \\
\hline & & $\begin{array}{l}\% \text { of } \\
\text { Total }\end{array}$ & $69.9 \%$ & $20.5 \%$ & $3.6 \%$ & $6.0 \%$ & $100.0 \%$ \\
\hline
\end{tabular}




\section{Chi-Square Tests}

\begin{tabular}{|c|c|c|c|}
\hline & Value & $\mathrm{df}$ & $\begin{array}{l}\text { Asymp. Sig. } \\
\text { (2-sided) }\end{array}$ \\
\hline Pearson Chi-Square & $25,595^{a}$ & $\overline{9}$ & .002 \\
\hline Likelihood Ratio & 27,464 & 9 & .001 \\
\hline $\begin{array}{l}\text { Linear-by-Linear } \\
\text { Association }\end{array}$ & 3,269 & 1 & .071 \\
\hline $\mathrm{N}$ of Valid Cases & 83 & & \\
\hline
\end{tabular}

a. 10 cells $(62.5 \%)$ have expected count less than 5 . The minimum expected count is 47 .

In the open-ended question (10) "what do you propose with regard to improving your satisfaction from the content of your work?", the suggestions of the respondents are presented in Table 5.

Table 5: Distribution of frequencies and relative \% of teachers according to their proposals with regard to their satisfaction from the content of their work

\begin{tabular}{|c|c|c|c|c|c|}
\hline \multicolumn{2}{|c|}{$\begin{array}{l}\text { Proposals with regard to their } \\
\text { satisfaction from the content of } \\
\text { work }\end{array}$} & \multirow{2}{*}{$\begin{array}{r}\text { Frequency } \\
9\end{array}$} & \multirow{2}{*}{$\begin{array}{r}\text { Percent } \\
10.1\end{array}$} & \multirow{2}{*}{$\begin{array}{r}\text { Valid Percent } \\
52.9\end{array}$} & \multirow{2}{*}{$\begin{array}{r}\begin{array}{l}\text { Cumulative } \\
\text { Percent }\end{array} \\
52.9\end{array}$} \\
\hline Valid & $\begin{array}{l}\text { Implementation of } \\
\text { appropriate training } \\
\text { schemes }\end{array}$ & & & & \\
\hline & $\begin{array}{l}\text { Development of the } \\
\text { flexible zone scheme }\end{array}$ & 1 & 1.1 & 5.9 & 58.8 \\
\hline & $\begin{array}{l}\text { Ensuring appropriate } \\
\text { material and technical } \\
\text { infrastructure }\end{array}$ & 7 & 7.9 & 41.2 & 100.0 \\
\hline & Total & 17 & 19.1 & 100.0 & \\
\hline \multicolumn{2}{|c|}{ Missing } & 72 & 80.9 & & \\
\hline \multicolumn{2}{|l|}{ Total } & 89 & 100.0 & & \\
\hline
\end{tabular}

In the open-ended question (11) "what do you propose with regard to the means of your motivation for improving the effectiveness of your work?", the respondents' responses are presented in Table 6. 
Table 5: Distribution of frequencies and relative \% of teachers according to their proposals with regard to the means of their motivation for improving the effectiveness of their work

\begin{tabular}{|l|l|r|r|r|r|}
\hline $\begin{array}{c}\text { Proposals for motivation aimed at } \\
\text { improving effectiveness of work }\end{array}$ & Frequency & Percent & Valid Percent & $\begin{array}{c}\text { Cumulative } \\
\text { Percent }\end{array}$ \\
\hline Valid & $\begin{array}{l}\text { Utilisation of ICTs in the } \\
\text { teaching process }\end{array}$ & 3 & 3.4 & 15.8 & 15.8 \\
\cline { 2 - 6 } & Freedom of action & 1 & 1.1 & 5.3 & 21.1 \\
\cline { 2 - 6 } & $\begin{array}{l}\text { Development of solidarity } \\
\text { and mutual understanding }\end{array}$ & 3 & 3.4 & 15.8 & 36.8 \\
\cline { 2 - 6 } & $\begin{array}{l}\text { Continuous improvement } \\
\text { and career development }\end{array}$ & 12 & 13.5 & 63.2 & 100.0 \\
\cline { 2 - 6 } & Total & 19 & 21.3 & 100.0 & \\
\hline Missing & System & 70 & 78.7 & & \\
\hline Total & & 89 & 100.0 & & \\
\hline
\end{tabular}

\section{Research Results Discussion}

A comprehensive evaluation of the individual findings leads to specific remarks concerning the satisfaction/ dissatisfaction and the motivation of teachers, which are detailed below.

As regards the prioritisation of the significance of specific factors of satisfaction, we asked the respondents to prioritise the significance of each factor, using numeral 1 for the most significant factor and numeral 10 for the least significant one. Out of the ten proposed factors concerning the satisfaction of teachers from their work, the support from the school management factor exhibits the highest prioritisation, with a weighted average prioritisation of significance equalling 8.039 on the 1-10 scale. The significance of the next factor is 7.2 and of that with the lowest significance being 3.634. The majority of respondents (44.3\%) select the support from the school management factor as being the most significant satisfaction factor, while their vast majority $(52.3 \%)$ prioritise it in the three first positions of their selections. This result is conducive to the remark that the support from the school management factor is, for the teachers of our sample, the most significant factor of satisfaction. The strong and undisputed recognition of the support from the school management factor is a particularly interesting finding of this research, which must be utilised by both the planners and researchers of educational policy in the educational human resource management domain, as well as by scholars in the field. The proper utilisation of the support from the school management factor is a cornerstone for improving content effectiveness in schools providing educational work. 
The teachers of our sample prioritise, in descending order, the factors observance of the school operating rules, the existence of an internal operating regulation, and the support from parents, in the second, third, and fourth position of their selections respectively, attributing to them significance values of 7.2, 7.104 and 5.593, respectively. The teachers of our sample prioritise, in positions 1-3, the factors observance of the school operating rules and existence of an internal operating regulation, with their respective percentages being 63.1 and $57 \%$, respectively, and they prioritise in the $9^{\text {th }}$ and $10^{\text {th }}$ position, the factors observance of the school operating rules $(3.4 \%)$ and existence of an internal operating regulation $(10.5 \%)$, respectively. Finally, only a small percentage (21\%) of teachers prioritise the recognition of their work from the parents in the first positions of their selections, while an even smaller percentage (13\%) rank such recognition in the last two positions of the scale, from the perspective of its significance, with a significance coefficient of 5.215. Also, the respondents place the factors sense of job security ensured by their job, the interest of colleagues and the stability of the teaching staff in the $6^{\text {th }}, 7^{\text {th }}$ and $8^{\text {th }}$ position of the priority list, respectively, using significance prioritisation coefficients of 5.113, 5.075 and 4.43, respectively. Finally, the results of the study show that the teachers of our sample, with a percentage of $42 \%$, rank the existence of a written plan for school development in the $9^{\text {th }}$ position of their priority list, with the prioritisation coefficient of the significance of the specific factor equalling 4.081. Finally, the respondents place the social recognition factor in the last position of their priority list (43.4\%; significance coefficient: 3.634$)$.

Of particular interest is also the finding of our study regarding the determination of the significance factor of basic parameters that contribute to the motivation of teachers. In this respect, the respondents replied that, in a descending order, they regard the following motivation factors as being particularly significant: interest for work (83.1\%); work creativity (75.3\%); freedom of action (72.7\%); establishment of processes for the continuous improvement of work (63.2\%); existence of a culture of

support, solidarity and mutual understanding (61.6\%); connection of personal development with professional development (52.3\%); satisfaction from one's earnings (44.3\%); recognition (38.8\%); need for success $(32.2 \%)$; and, finally, prospects for professional development (29.5\%). This result is consistent with findings reported in the literature of the field (Herzberg, in Kantas 1998) and concurs to the remark that the factors (motives) of work satisfaction are: achievement, recognition of one's work, work as such, accountability, and prospects for career development. Also, based on this result, it may be sustained that the motivation of teachers is linked primarily with endogenous factors of professional satisfaction (Warr, 2005), among which the most important ones are: interest for work, work creativity and freedom of action. 
As pertains to the determination of the factors that contribute to the respondents' disappointment from their work, the following are prioritised as being highly important or important: lack of appropriate material and technical infrastructure (100\%); inadequate school unit funding (100\%); non-satisfaction from one's earnings (100\%); absence of appropriate training schemes $(89.8 \%)$; existence of conflicts at the workplace (89.6\%); insufficient information about institutionalised educational changes $(85.2 \%)$; exclusion from the decision-making centres $(81.8 \%)$; and, finally, inadequate training at the level of their basic studies (79\%). This result is partly consistent with data reported in the relevant literature (Maslach \& Schaugeli 1993; Kraviwti, 2013; Grammatikou, 2010; Kantas, 1992), according to which the main sources of teacher dissatisfaction are to be found in issues of insufficient material and technical infrastructure and insufficient funding of the school units, in the pecuniary earnings and in the career and personal development prospects linked with the teacher's jobs. In addition, important factors of dissatisfaction are, also, increased workload, increased time spent by teachers on administrative school issues, difficulty in balancing their professional and personal life, and the overall view of society for teachers (Rhodes, Nevill \& Allan, 2004).

Moreover, given the significance of the specific question for our research, we correlated it with the respondents' total years of service in the educational system. The replies suggest that, mostly, teachers with fewer years of service consider the existence of conflicts at the workplace to be a very important or important factor contributing to their disappointment from work. This finding is consistent also with data of a relevant research (Joseph \& Schumacher, 1995), based on which, demographic factors affect the disappointment, albeit not the satisfaction, of teachers. It also confirms Herzberg's view, that professional satisfaction is linked directly to endogenous factors, while disappointment is rather suggestive of adverse external conditions.

With regard to the general question "what do you propose with regard to improving your satisfaction from the content of your work?", it could be suggested that the respondents, in their majority, view the improvement of their satisfaction in relation to the content of their work through the following lenses: (a) the implementation of appropriate further training schemes $(52.9 \%)$; (b) ensuring the appropriate material and technical infrastructure $(41.2 \%)$; and (c) the development of the flexible zone institution (5.9\%). This result is partly consistent also with data derived from the relevant literature (Dinham \& Scott, 2000). Based on the latter, in order to improve the teachers' professional satisfaction, it is necessary to enhance the intra-school factors that are related to the school climate, the leadership behaviour of the school manager, the school infrastructure and the school's reputation. Such factors may be controlled and determined by the schools alone, and by their managers who exercise a leadership role. 
Finally, as regards the general question "what do you propose with regard to the means of your motivation for improving the effectiveness of your work?", the views of the majority of the respondents focus, in a descending order: (a) on the safeguarding of continuous improvement processes aimed at their personal and professional development $(63.2 \%)$; (b) on the utilisation of ICTs in the teaching process $(15.8 \%)$; (c) on the development of solidarity and mutual understanding processes $(15.8 \%)$; and (d) on the freedom of action (5.3\%). This result is partly consistent also with data derived from the relevant literature (Dinham \& Scott, 1998, Kyriakou, 2001, Kantas, 1992, Dimitropoulos, 1998), according to which important motivation factors for improving teachers' work effectiveness include, inter alia, satisfaction from the pupils' performance, personal professional development, career development prospects and esprit de corps.

\section{Conclusions}

Based on the findings of this research and the preceding analysis, the following conclusions can be formulated.

The views of the majority of the respondents in relation to the prioritisation of the significance of specific factors that are mainly related to the content of their working life at the micro-level of the school unit and the school class, focus in descending order, on: their support from the school management; the observance of the school's operating rules; the existence of an internal operating regulation for the school examined; the support of the teachers by the parents; the recognition of the teachers' work by the parents; the sense of security offered by their work; the interest of their colleagues; the stability of the teaching staff; the existence of a written plan for school development; and social recognition.

The highest percentages of the factors, selected by the respondents in relation to the determination of the degree of significance of the basic parameters that affect their motivation in the workplace, focus mainly on interest for work on the creativity of work, and on the freedom of action. In contrast, lower percentages are observed in teachers who view as important motivating factors the establishment of continuous work development processes; the existence of a culture of support, solidarity and mutual understanding; and the connection of personal development with professional development. Even lower percentages are observed in relation to satisfaction from one's earnings; recognition; the need for success; and, finally, prospects for professional development.

The views of the majority of teachers of our sample in relation to the determination of the factors that contribute to their disappointment from their work are conducive to the observation that the most significant factors of disappointment are: the lack of 
appropriate material and technical infrastructure; the insufficient school unit funding; and the dissatisfaction of teachers from their earnings. In contrast, less significant factors are considered to be the lack of appropriate training schemes; the existence of conflicts at the workplace; and the insufficient information of teachers about institutionalised educational changes. Finally, the lowest degree of significance is attributed by the respondents to their exclusion from the decision-making centres; and to their inadequate training at the level of their basic studies.

As regards the improvement of the teachers' satisfaction from the content of their work, the majority of respondents consider the following factors as very important, in a descending order: the implementation of appropriate training schemes; and ensuring the necessary material and technical infrastructure. In contrast, much lesser importance is attributed to the development of the free zone institution.

The views of the majority of teachers of our sample in relation to the means of their motivation for improving the effectiveness of their work suggest that the most important motivating factor is ensuring processes of continuous improvement of their personal and professional development, while less important factors are the utilisation of ICTs in the teaching process; and the development of processes of solidarity and mutual understanding. Of even lesser importance is the factor of freedom of action.

Based on the above findings and considering also that the improvement of the level of effectiveness and of the quality of the teaching and learning process is linked directly to the level of teacher satisfaction/ dissatisfaction and motivation, it is concluded that the need to improve the levels of the teachers' professional satisfaction is indeed a challenge, a requirement and indeed a necessary condition for meeting the needs of the educational and the social system alike.

The study results discussion has brought to the surface important aspects that may prove valuable for future research. More specifically, the co-examination of the variables of the teachers' satisfaction/ dissatisfaction from internal school factors that are related to the context of the teachers' working life at the micro-level of the school unit and the school class, of the effectiveness of the school and of the transformative/ interactive process that obtains between the teachers, can be further researched, so as to study in greater depth all of the parameters that are linked to issues such as the determination of correlations and interactions between such factors. 


\section{References}

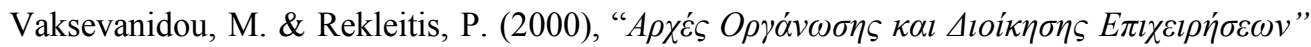
(in Greek), ITYE.

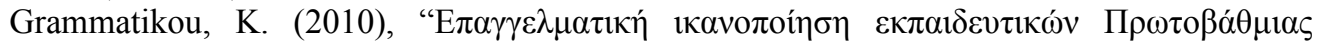

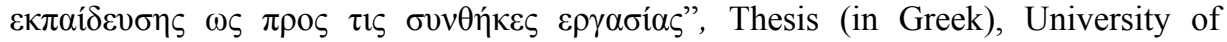
Harokopeio, Athens.

Darra, M. (2006), "Productivity Improvements in Education: A Replay", European Research Studies Journal, Vol. IX, 3-4, pp. 101-124.

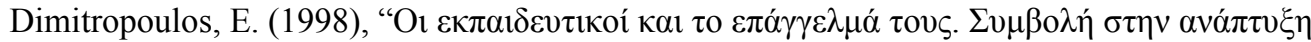

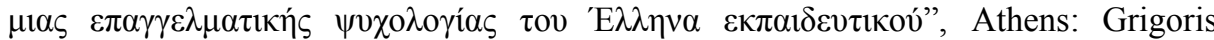
Publishing (in Greek).

Gruneberg, M. (1979), Understanding Job satisfaction, Great Britain: the Macmillan Press Ltd.

Dinham, S. \& Scott, C. (1998), "A three domain model of teacher and school executive satisfaction", Journal of Educational Administration, 36(4), pp. 362-378.

Dinham, S. \& Scott, C. (2000),"Moving into the third, outer domain of teacher satisfaction", Journal of Educational Administration, 36(4), pp. 379-39.

Eliophotou-Menon, M., Papanastasiou, E. \& Zempylas, M. (2008), "Examining the relationship of job satisfaction to teacher and organizational variables: Evidence from Cyprus", Journal of the Common wealth Council for Educational Administration \& Management, 36(3), pp. 75-86.

Evans, L. (1999), Teacher morale, job satisfaction and motivation, London: Paul Chapman.

Herzberg, F. (1957), The Motivation to work, 2nd Edition", John Wiley, available at: http://barbradozier.wordpress.com/2011/12/14/theory-of-herzberg-motivator-factors/ [10/1/2014].

Joseph, A. and Schumacher, P. (1995), "Factors contributing to job satisfaction in higher education", Educational Journals, 111, p.51.

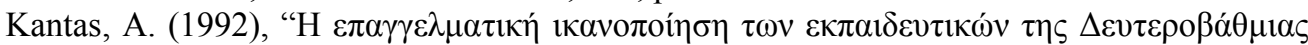

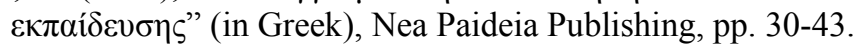

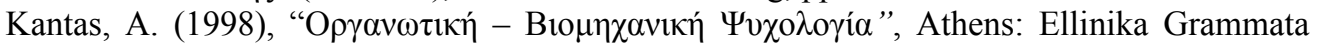
Publishing (in Greek).

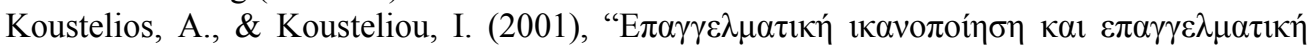

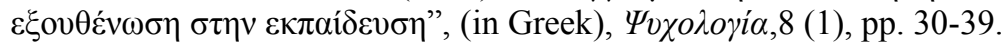

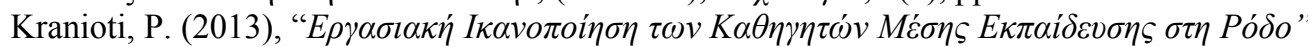

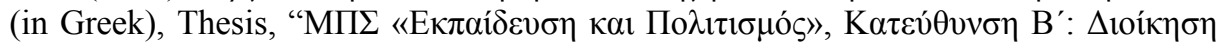

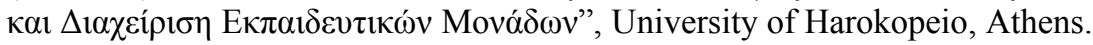

Koustelios, A. (2001), "Personal characteristics and job satisfaction of Greek teachers", International Journal of Educational Management, 15 (7), pp. 354-358.

Koustelios, A. (2005), "Physical education teachers' in Greece: Are they satisfied?" International Journal of Physical Education, 42(2), pp. 85-90.

Kyriacou, C. (2001), "Teacher stress: Directions for future research", Educational Review, 53(1), pp. 27-35.

Locke, E. A. (1976), "The nature and causes of job satisfaction" in M. D. Dunnette (Ed), Handbook of industrial and organizational psychology, Chicago: Rand MacNally, pp. 1297-1343. 
Ma, X. \& MacMillan, R. (1999), "Influences of workplace conditions on teachers' job satisfaction", The Journal of Educational Research, 93(1), pp. 39-47.

Maslach, C. (1982), Burnout: The cost of caring, Hillslade, NJ: Prentice Hall.

Maslach, C., \& Jackson, S.E. (1986), Maslach burnout inventory, Palo Alto: Consulting Psychologists Press.

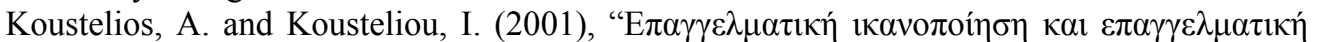

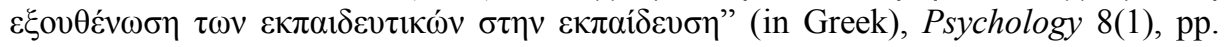
30-39.

Maslach, C. \& Schaugeli, W. (1993), "Historical and conceptual development of burnout", in Schaufeli W., Maslach, C., \& Mark, T., (Eds), Professional burnout Recent developments in theory and research, London: Taylor \& Francis.

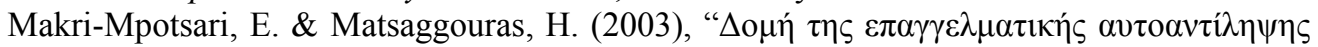

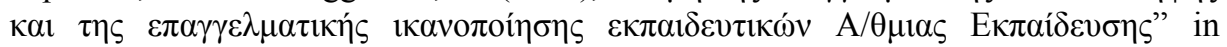

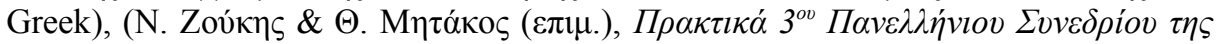

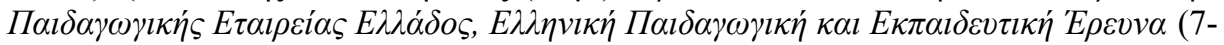

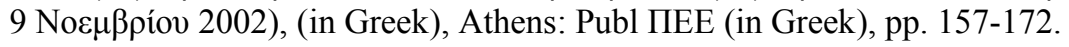

Rhodes, C., Nevill, A., \& Allan, J. (2004), "Valuing and supporting teachers: A survey of teacher satisfaction. Dissatisfaction morale and retention within an English Local Education Authority", Research in Education, 71, pp. 74-87.

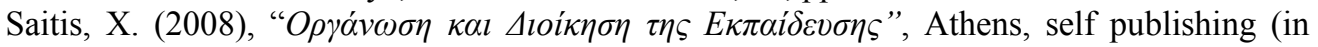
Greek).

Vroom, V.H. (1964), Work and Motivation, New York: John Wiley and Sons, Inc.

Vroom, V.H. \& MacCrimmon, K.R. (1968), "Toward a stochastic Model of Managerial Careers", Administrative Science Quarterly, 13(1), pp. 26-46.

Warr, P. (2005), "Work, well being and mental Health", In Barling, J., Kelloway. K., \& Frone, M.(Eds), Handbook of Work Stress, New York: Sage.

Zembylas, M. \& Papanastasiou, E. (2004)., Job satisfaction among school teachers in Cyprus. Journal of Educational Administration, 42(3), pp. 357-374. 